$5^{\text {th }}$ International Conference on Innovation in Science and Technology

Barcelona - Spain

ISTCONF

7 - 9 December, 2018

\title{
Justification of the choice of the generation capacity
}

\author{
Vasenin Dmitrii, Sotnikova Olga, Schetinin Nikolay, Mastiukevich Daria
}

University/Institute

Voronezh State Technical University

\begin{abstract}
The unified electric power system is based on a hierarchical principle. It provides balance of energy generation, allocation and consumption in terms of territory to achieve energy security of regions and opportunity of intersystem exchange of power flow and energy during normal and accident modes for increasing productivity of energy consortium.

An electrical grid plays an important role in electric power modernization. It is a structure that provides connection between generation and consumer. Latest technologies applying for grids allow to create an effectively functioning system that can be equipped with modern diagnostic information systems, automation system to control all the elements included in the process of production, transmission and allocation of electric energy. The article devotes to the creation of an intelligent power system with an active-adaptive network. An electrical grid is turning into active element. Its characteristics are changing according to the operation mode of the electric power system.

In recent decades a Smart Grid technology is developing in advanced countries. There are lots of pioneering projects in which using of "smart consumption meters", "smart homes", wind and solar energy helps to save consumers' money. The concept of Smart Grid aims at expending of capacity and energy market to ultimate customer and making these markets accessible for consumers. Thus the performance and efficiency of the market will be improved.

Our research work is devoted to creating a calculation method and justification of the choice of the generation capacity in developing and technical re-equipping of current power interconnections.
\end{abstract}

Keywords: generation capacity, the unified electric power system, Smart Grid, wind and solar energy, transmission and allocation of energy. 